\title{
O PRINCÍPIO DA DIGNIDADE DA PESSOA HUMANA E O PRESO PORTADOR DE DEFICIÊNCIA FÍSICA: RUMO À ADEQUAÇÃO FÍSICA DOS ESTABELECIMENTOS PRISIONAIS
}

\section{Emanoele Cristina da Silva Carraro'}

Resumo: O presente trabalho aborda de forma ampla a correlação existente entre o Princípio da Dignidade da Pessoa Humana e o preso portador de necessidades especiais, no que tange sua mantença intra-cárcere. Tem por objetivo proceder ao levantamento das condições físicas dos estabelecimentos prisionais, analisar se legislação estabelece normas e diretrizes com relação a adequação física e legal dos estabelecimentos prisionais, examinar a existência de tratamento de ajuda e suporte de assistência para os portadores de necessidades especiais, nas casas penitenciárias, verificar se os estabelecimentos prisionais estão adequados e/ou possuem condições de receber presos portadores de deficiência física e investigar quais são os direitos que os portadores de necessidades especiais possuem junto à atual sociedade. Ao final espera-se ter contribuído com a sociedade no sentido de informar às pessoas acerca do assunto tratado, qual seja, a possibilidade de adequação do sistema prisional para a recepção de presos com deficiência física, tema este que requer a participação de toda a sociedade e do Poder Público para sua solução, pois estas pessoas

1 Advogada (OAB/SC n. 35.655). Bacharel em Direito pela Universidade do Oeste de Santa Catarina - UNOESC Campus de Xanxerê. E-mail: eumanuxxm@hotmail.com 
possuem igualmente em seu favor o princípio da dignidade da pessoa humana no tocante ao cumprimento da restrição de sua liberdade.

Palavras-chave: Dignidade da pessoa humana. Preso. Necessidades especiais.

\section{INTRODUÇÃO}

A dignidade da pessoa humana pode ser entendida como a qualidade intrínseca e distintiva de cada pessoa que a torna merecedora de respeito e consideração por parte do Estado e dos outros indivíduos. Portanto, assegura a todos nós as condições existenciais mínimas para uma vida saudável, além de proporcionar a participação ativa e co-responsável nos destinos da própria existência e da vida em comunhão com os demais seres humanos.

Como desdobramento da dignidade da pessoa humana, tem-se a necessidade de proteção do portador de deficiência, assim entendido aquele indivíduo que apresenta limitações físicas e/ou mentais, adotando-se ações positivas que lhe permitam a igualdade em direitos com aqueles tidos como normais.

De outro norte, é de conhecimento geral que o sistema prisional brasileiro está longe de ser algo desejável, sendo vários os problemas que o afetam e poucas as soluções apresentadas, o que transforma nossas prisões em verdadeiros depósitos de pessoas.

Neste contexto, a falta na legislação pátria de regramento específico acerca do cumprimento da pena por deficientes físicos, aliada à escassez de estudos doutrinários que se dediquem a tratar, de forma aprofundada, esta possibilidade, motivou a escolha do tema para elaboração deste artigo.

O descaso do Poder Público quanto à implementação de melhoras no sistema penitenciário brasileiro, com o fim de tornar digno o cumprimento de pena de pessoas sem limitação 
física, já é de conhecimento de todos. Mas e como fica a dignidade nesse resgate quando a pessoa é portadora de necessidades especiais e nenhum estabelecimento penal é adaptado para sua recepção?

Assim, faz-se necessário um debate sobre as dificuldades diárias enfrentadas pelo preso portador de deficiência física, somadas à falta de estrutura para sua recepção.

Oportuno registrar que não se pretende dar ênfase de superstar ao preso com deficiência física ou estabelecer privilégios por conta dessa condição. $\mathrm{O}$ que se busca no presente trabalho é deixar evidente a falta de estrutura de nossos presídios para recepção do portador de limitações, como forma de reforçar a ideia de que a condição de privado de liberdade de locomoção não pode retirar do preso outros direitos, especialmente à dignidade como pessoa.

Por derradeiro, cumpre ressaltar que a dignidade humana, elevada ao status constitucional de garantia fundamental da pessoa, não pode ser afrontada pelo Poder Estatal, principalmente em uma época que mundialmente se busca preservar o respeito aos direitos do homem, sendo esta uma das razões porque se propõe o estudo do tema.

\section{DESENVOLVIMENTO}

Historicamente se tem registro das lutas para a efetivação da igualdade entre os seres, tanto em direitos como em deveres, e somos todos sabedores de que, muito embora não sejamos parecidos fisicamente, a mesma lei nos rege. Neste sentido, a busca por respostas a perguntas como: existem direitos e deveres distintos para as pessoas tidas como normais e aquelas que apresentam algum tipo de limitação, insistem em se manifestar.

Sendo a diferença algo intrínseco à pessoa, como uma espécie de manifestação singular, certa se faz a idéia de limitação para entrada/permanência em determinados lugares ou a concretização de determinados direitos. 
Neste esteio, os direitos da pessoa portadora de deficiência "constituem tema ou fenômeno que expressa acentuado grau de complexidade" (ASSIS, 2005, p. 49), no que se refere "à produção de normas positivas garantidores de tais direitos" (ASSIS, 2005, p. 49), pois "antes de estarem escritos numa constituição ou num texto jurídico, estão anunciados sob a forma de movimentos sociais [...] que evoluem numa outra maneira de sentir e pensar" (ROBERT, 1999, p. 4-5).

$\mathrm{Ab}$ initio, insta esclarecer o sentido etimológico das expressões que mais serão utilizadas neste trabalho, quais sejam, princípio, dignidade e pessoa.

Pessoa designa o homem como sujeito de direitos e obrigações, no desempenho da função que lhe é dada pelo Direito (MARTINS, 2004, p. 115).

Já "o termo dignidade possui quase sempre o sentido de honestidade e honradez" (MARTINS, 2004, p. 113). Acreditando que a dignidade é a essência do ser humano, Sarlet (2001, p. 122) esclarece que ela é um bem jurídico absoluto, sendo, portanto, inalienável, irrenunciável e intangível. Em linguagem jurídica, a origem da expressão dignidade serviu para designar o encargo ou o título que poderia ser conferido a uma pessoa e, por extensão, acentuar o respeito que esta pessoa deve ao mandato ou à função que exerce (DELPÉRÉE, Francis, p. 153 apud MARTINS, 2004, p. 114).

A dignidade era tida como "a qualidade que, por ser inerente ao ser humano, o distinguia das demais criaturas, no sentido de que todos os seres humanos são dotados da mesma dignidade", dando a idéia de que "todos os seres humanos, no que diz com a sua natureza, são iguais em dignidade" (SARLET, 2004, p. 30-31).

Advindo do latim, principiu, o vocábulo princípio significa "causa primária, um elemento predominante na constituição de um corpo orgânico, preceitos, regras, leis, a base, o germe" (FERREIRA, 2004, p. 654). 
Os princípios "não proíbem, permitem ou exigem algo em termos" (CANOTILHO [200-], p. 1255), como querendo dizer que nos princípios repousa a essência de um mandamento

Por fim, podemos dizer que os princípios desempenham a função de dar fundamento material e formal às demais regras integrantes do sistema, pois exercem uma função muito importante, uma vez que iluminam a interpretação das normas jurídicas (NUNES, 2002, p. 38).

Contudo, as palavras princípio, dignidade e pessoa, nada fazem sozinhas: ficam ainda mais fortes quando utilizadas conjuntamente: princípio da dignidade da pessoa humana.

Mas então, o que vem a ser essa dignidade da pessoa humana? Ela nos traz alguma segurança? Adentrando na discussão, temos por dignidade da pessoa humana a qualidade intrínseca e distintiva de cada ser humano que o faz merecedor do mesmo respeito e consideração por parte do Estado (SARLET, 2001, p. 60). Assim, tal direito assegura à pessoa as condições existenciais mínimas para uma vida saudável, além de propiciar e promover sua participação ativa e co-responsável nos destinos da própria existência e da vida em comunhão com os demais seres humanos.

Assim, o conteúdo da dignidade da pessoa humana pode ser identificado como o núcleo essencial dos direitos fundamentais, uma vez que, como já comentado, é um elemento base para a concretização dos demais direitos.

Em nossas Constituições Federais, podemos encontrar a passagem do princípio em fomento. Todas almejaram resguardar a importância do princípio, pois, desde sempre, o mesmo foi reconhecido.

A primeira referência ao tema da dignidade da pessoa humana pode ser encontrada, ainda que de modo incipiente em um outro contexto, já ao tempo da Constituição de 1934, na qual "se observa expressa referência à necessidade de que a ordem econômica fosse organizada de modo que possibilitasse a todos "existência digna" (MARTINS, 2004, p. 47). Desde 
aquele tempo, observou-se a materialização da dignidade da pessoa humana.

E toda essa garantia ditada pela Norma Maior é assegurada, pois a dignidade da pessoa humana é "o primeiro fundamento de todo o sistema constitucional posto e o último arcabouço da guarida dos direitos individuais" (NUNES, 2002, p. 45).

No tocante a aplicabilidade da norma em questão, é tarefa do profissional do Direito tornar compreensível o conjunto de normas ditadas pelo Estado (ASSIS, 2005, p. 174); "é como se o operador do direito fosse um especialista em montar quebra-cabeças, cujas peças são as normas emanadas da vontade soberana estatal que estão espalhadas nos diversos instrumentos normativos" (ASSIS, 2005, p. 174).

A nossa atual Constituição, em seu artigo $1^{\circ}$, inciso III $^{2}$, não contém apenas uma declaração de conteúdo ético e moral (SARLET, 2001, p. 72): o valor jurídico protegido pelo artigo mencionado torna-o fundamental na construção do ser humano almejado pela sociedade, tanto que o Constituinte adotou expressamente "pessoa humana", para se qualificar como pessoa e gozar da proteção constitucional (MARTINS, 2004, p. 118). Logo nenhum princípio é mais valioso para materializar a idéia proposta pela Constituição que o princípio da dignidade da pessoa humana.

Quanto ao sentido etimológico do vocábulo deficiência, Robert (1999, p. 125), ensina que ela "é segundo dicionários de língua portuguesa, a falta, a lacuna, a imperfeição e a insuficiência de algo", e que "ser deficiente significa apenas ser imperfeito por não possuir algo que o incapacita no momento de exercer sua liberdade de ser e estar".

Com uma visão mais moderna, Assis (2005, p. 244-245), esclarece que "o que define a pessoa portadora de deficiência

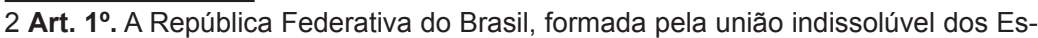
tados e Municípios e do Distrito Federal, constitui-se em Estado Democrático de Direito e tem como fundamentos:

$[\ldots]$

III - a dignidade da pessoa humana;

$[\ldots]$ 
não é a falta de um membro nem a visão ou a audição reduzida". Para ele, "o que caracteriza a pessoa portadora de deficiência é o grau de dificuldade de se relacionar, o grau de dificuldade de se integrar na sociedade", e mais: conclui dizendo que o "portador de deficiência é qualquer indivíduo que apresenta uma limitação física ou mental que o traga abaixo do padrão-modelo fixado pelo grupo".

Já para a Organização das Nações Unidas - ONU, em sua Resolução 33/3447, o termo pessoa deficiente "refere-se a qualquer pessoa incapaz de assegurar por si mesma, total ou parcialmente, as necessidades de uma vida individual ou social normal, em decorrência de uma deficiência, congênita ou não, em suas capacidades físicas ou mentais" (Resolução 33/3447, artigo $1^{\circ}$ ).

Nacionalmente, o Decreto Legislativo 186/08 em seu artigo primeiro define pessoas com deficiência como "aqueles que têm impedimentos de longo prazo de natureza mental, intelectual ou sensorial, os quais em interação com diversas barreiras, podem obstruir sua participação plena e efetiva na sociedade de condições com as demais pessoas" (BALDI, 2009). Mas nem sempre foi assim.

As primeiras leis escritas estampavam as contradições correlacionadas com as pessoas portadoras de deficiência. As leis antigas demonstravam que a ação dos governos em relação às pessoas com deficiência articulava-se na linha de uma política de extermínio (ASSIS, 2005, p. 63), onde "o deficiente, por sua disformidade ou inutilidade para os fins imediatos da tribo ou da nação, devia ser exterminado" (OLIVEIRA, 1981, p. 12).

E para melhor compreender o esquecimento das pessoas que possuem alguma forma de deficiência, os dados estatísticos falam mais do que a história.

O Programa de Ação Mundial para as Pessoas com Deficiência (World Programme os Action Concerning Disabld), aprovado pela Assembléia Geral das Nações Unidas em dezembro de 1982, através Resolução n. 37/52, estima que pelo menos 10\% 
da população mundial são portadores de alguma deficiência física, mental ou sensorial (ASSIS, 2005, p. 31).

Em 2000, com o Censo IBGE-2000, o Brasil indicou que "14,5\% da população são portadores de deficiência" (ASSIS, 2005, p. 31). Mas o que mais chama atenção, é que de toda essa estatística, peritos estimaram que, "no Brasil, apenas 2\% das pessoas portadoras de deficiência são atendidos pelo Poder Público" (ASSIS, 2005, p. 32). De acordo com esse estudo, estima-se que, no mínimo, 350 milhões de pessoas portadoras de deficiência vivam em zonas que não dispõem dos serviços necessários para ajudá-las a superar suas limitações (ASSIS, 2005, p. 167).

Por essas razões, a partir da década de 1970, a ONU tem intensificado suas ações no sentido de combater as causas de deficiência, promovendo a inclusão social e a cidadania das pessoas portadoras de deficiência (ASSIS, 2005, p. 32).

Já a partir da década de 1980, as expressões anteriormente utilizadas para designar pessoas com limitação física (deficiente, inválido) vão sendo substituídas por pessoa portadora de deficiênciaª , que, se consagra na Constituição de 1988. Nossa doutrina também utiliza a expressão pessoa portadora de deficiência, mas há uma tendência no sentido de substituir essa expressão por pessoa portadora de necessidades especiais (ASSIS, 2005, p. 234).

Ademais, as pessoas interessadas preferem ser chamados de pessoas portadoras de necessidades especiais, porque o termo deficiência os coloca em uma situação de desvantagem em relação a outras pessoas, ao passo que o termo necessidades especiais não provoca essa impressão (ASSIS, 2005, p. 236).

Por fim, dizer que uma pessoa é portadora de deficiência não constitui discriminação: de fato, se uma pessoa tem uma limitação, isto é uma deficiência. O que devemos é combater

3 A expressão pessoa portadora de deficiência diminui o estigma da deficiência; é mais leve, mais elegante e diminui a situação de desvantagem que caracteriza esse grupo de indivíduos (ASSIS, 2005, p. 235). 
a discriminação com ações positivas, não recorrendo a eufemismos (MAZZILLI, 2003, p. 521). Por fim, não existe uma definição predominante do que tenha de ser utilizado pela sociedade. O que existe, é uma definição adotada como consensual, pois é menos agressiva aos mais interessados.

Visto doutrinariamente as expressões que se destacam neste artigo, necessário de faz adentramos ao tema proposto, especificamente falando deste conjunto de palavras em relação ao sistema prisional brasileiro.

Como se sabe, o sistema prisional está longe de ser algo desejável. Vários são os problemas que o afetam e poucas são as soluções para o caso. $O$ certo é que a grande maioria dos estabelecimentos penais possui falhas e sua melhora não pode ser algo utópico.

Até hoje "nos deparamos com um sistema penitenciário falido, no qual o preso é tratado com profundo desrespeito aos princípios e garantias contidos na nossa Constituição Federal" (SAVAZZONI, 2009).

O grande desrespeito está intimamente ligado à superlotação dos presídios. Sabe-se, de longa data, que o sistema carcerário do Brasil está à beira da falência. "A precariedade e as condições subumanas que os detentos vivem hoje" (CAMARGO, 2006), são dignas de filme.

Há notícias de que "nos estabelecimentos mais lotados, onde não existe nem lugar no chão, presos dormem amarrados às grades das celas ou pendurados em rede" (CAMARGO, 2006). E a fim de tornar pública a situação, no mês de junho do ano de 2010, o Ministério da Justiça, através do Sistema Integrado de Informações Penitenciárias (INFOPEN) elaborou uma tabela com os dados do sistema penitenciário do Estado de Santa Catarina.

Através dela é possível perceber que os números são alarmantes. São cerca de 236,67 presos por cem mil habitantes. Só no Presídio Regional de Xanxerê, são 267 presos para 130 
vagas $^{4}$, ou seja, são 137 presos a mais do permitido, e que estão "estocados" nas celas.

Neste contexto fica evidente que "as prisões e penitenciárias brasileiras são verdadeiros depósitos humanos, onde homens e mulheres são deixados aos montes sem o mínimo de dignidade como seres humanos que são" (LIMA, 2010) e nem se lembra que "a prisão existe por castigo e não para castigar" (CAMARGO, 2006).

Vale lembrar que a superpopulação carcerária "é prática que vai contra a Constituição Federal, a Lei de Execução Penal e vários tratados internacionais dos quais o Brasil é signatário" (COSTA, 2008). Esta prática "representa desprezo indesculpável ao ser humano que passa a ser tratado não como sujeito de direitos, mas como objeto" (COSTA, 2008). Digo que esta prática vai contra a Constituição Federal, porque a Lei Maior, em seu artigo $5^{\circ}$, inciso XLIX, dispõe que "é assegurado aos presos o respeito à integridade física e moral”. E mais: vai contra a Lei de Execução Penal, pois o artigo 84 desta assegura que "o estabelecimento penal deverá ter lotação compatível com a sua estrutura e finalidade”. Como podemos verificar, nenhum dos preceitos acima mencionados é observado.

Outro ponto a ser salientado é que a Lei de Execuções Penais, nada dispõe acerca do cumprimento de pena por pessoas com deficiência física, "minoria esta que não vê seus direitos de cidadão serem garantidos ou sequer mencionados na Lei de Execuções Penais" (SAVAZZONI, 2009).

Não existe na legislação lei que regulamente o cumprimento de pena, em regime fechado, por estas pessoas que merecem atenção especial, atenção que deve ser oferecida igualmente ao preso dito como 'normal'. Tal esquecimento fere o princípio da dignidade da pessoa humana, pois "antes de ser um apenado, este sujeito é um cidadão, e como cidadão deveria ter seus direitos e garantias fundamentais respeitados" (SAVAZZONI, 2009).

4 Dados colhidos pela autora, em visita ao referido estabelecimento penal em data de 09.03.2010. 
Embora não haja previsão expressa neste sentido, é importante destacar que "a estruturação dos presídios deve também atender, especificamente, aos apenados portadores de necessidades especiais, conforme garante de maneira implícita a Constituição Federal em seu artigo 5º, incisos III, XLVIII e XLIX" (SAVAZZONI, 2009):

No que tange às condições de acessibilidade da pessoa portadora de deficiência dentro do sistema penitenciário nacional (levando-se em conta a complexidade deste termo, onde se engloba o direito à locomoção, ao transporte, à retirada das barreiras arquitetônicas, à informação, e de acesso ao mobiliário urbano), cumpre realçar o entendimento de que "o indivíduo privado de sua liberdade não se encontra, porém, privado de seus direitos garantidos constitucionalmente, norteados pelo princípio da dignidade da pessoa humana" (SAVAZZONI, 2009).

Após termos visto o que é o princípio da dignidade da pessoa humana, conceituado a prisão e estudarmos em quais situações esse princípio foi violado, cabe, por fim, utilizá-lo em casos com presos portadores de necessidades especiais.

Em nossa legislação, diga-se de passagem, deveras extensa, existem algumas normas específicas acerca da acessibilidade. Contudo, nenhuma delas é voltada para a construção ou reforma de presídios e penitenciárias, a fim de torná-los aptos a recepcionar presos que possuam alguma deficiência física.

Destarte, utilizando a analogia é possível propiciar aos sujeitos em destaque (deficientes físicos) uma melhor qualidade no cumprimento da pena privativa de liberdade.

5 Art. $5^{\circ}$. Todos são iguais perante a lei, sem distinção de qualquer natureza, garantindo-se aos brasileiros e aos estrangeiros residentes no País a inviolabilidade do direito à vida, à liberdade, à igualdade, à segurança e à propriedade, nos termos seguintes:

[...]

III - ninguém será submetido a tortura nem a tratamento desumano ou degradante; $[\ldots]$

XLVIII - a pena será cumprida em estabelecimentos distintos, de acordo com a natureza do delito, a idade e o sexo do apenado;

$[\ldots]$

XLIX - é assegurado aos presos o respeito à integridade física e moral; $[\ldots]$ 
Mirabete (2010) explica que "a analogia é uma forma de auto-integração da lei", pois na "lacuna involuntária desta, aplica-se ao fato não regulado expressamente um dispositivo que disciplina hipótese semelhante" (MIRABETE, 2010). Consiste nada mais do que uma "extensão de uma norma jurídica de um caso previsto a um caso não previsto com fundamento na semelhança entre os dois casos" (MIRABETE, 2010).

Contudo, a analogia somente pode ser aplicada "na lacuna involuntária da lei, não sendo cabível nas hipóteses em que a lei processual tem caráter inflexível, taxativo" (MIRABETE, 2010).

Pois bem, necessário utilizar a analogia no presente trabalho, pois, do estudo a Lei de Execução Penal constata-se que ela não reserva nenhum artigo para tratar do assunto, qual seja, o cumprimento de pena privativa de liberdade por preso que possua alguma espécie de necessidade especial.

A realidade urbanística e arquitetônica da maioria das cidades demonstra que a pessoa portadora de deficiência não consegue sair de casa, do seu espaço privado. Enquanto essa situação permanecer, "o portador de deficiência está excluído da cidadania, do convívio social, porque lhe é negado o direito de adentrar o espaço público” (ASSIS, 2005, p. 470).

A arquiteta Adriana Romeiro de Almeida Prado, sendo citada pelo doutrinador Olney Queiroz Assis (2005, p. 471) confirma: "o que se observa é que não há muita preocupação em se projetar objetos, edifícios, espaços e transporte cujo desenho seja acessível às pessoas com deficiência [...]", e que "possibilitar a sua integração ao meio que as cerca seria permitir uma melhor integração à sociedade".

E no intuito de diminuir as barreiras foram criadas as Leis n. 10.098/2000, 10.048/2000 e 7.853/1989.

A Lei n. 10.098/2000 estabelece normas gerais e critérios básicos para a promoção da acessibilidade das pessoas portadoras de deficiência ou com mobilidade reduzida. Dentre os capítulos, destacam-se dois, os quais serão utilizados neste trabalho: capítulo quatro e dez. 
O capítulo quatro trata da acessibilidade dos edifícios públicos ou de uso coletivo. Utiliza-se ele, pois o presente trabalho é direcionado à adequação das casas penitenciárias para a recepção de presos com limitação motora.

O artigo 11 da Lei dispõe que "a construção, ampliação ou reforma de edifícios públicos ou privados destinados ao uso coletivo deverão ser executadas de modo que sejam ou se tornem acessíveis às pessoas portadoras de deficiência ou com mobilidade reduzida". A fim de se fazer cumprir o disposto, devem existir vagas de garagem disponíveis para veículos que transportem pessoas portadoras de deficiência com dificuldade de locomoção permanente, pelo menos um dos acessos ao interior da edificação deverá estar livre de barreiras arquitetônicas e de obstáculos que impeçam ou dificultem a acessibilidade de pessoa portadora de deficiência ou com mobilidade reduzida e os edifícios deverão dispor, pelo menos, de um banheiro acessível.

A Lei estabeleceu quais são os parâmetros para a adequação de logradouros que, quando de sua construção, não eram obrigados a adaptar seu funcionamento, para pessoa com necessidades especiais. Dentre os parâmetros, destacam-se dois, que podem, com tranqüilidade, ser utilizados em presídios e penitenciárias, quais sejam: a liberdade de obstáculos que impeçam ou dificultem a acessibilidade e o banheiro acessível, inclusive com equipamentos e acessórios para a utilização da pessoa necessitada.

Já no capítulo dez da mesma lei, há a seguinte disposição:

Art. 23. A Administração Pública federal direta e indireta destinará, anualmente, dotação orçamentária para as adaptações, eliminações e supressões de barreiras arquitetônicas existentes nos edifícios de uso público de sua propriedade e naqueles que estejam sob sua administração ou uso.

Parágrafo único. A implementação das adaptações, eliminações e supressões de barreiras arqui- 
tetônicas referidas no caput deste artigo deverá ser iniciada a partir do primeiro ano de vigência desta Lei.

Art. 24. O Poder Público promoverá campanhas informativas e educativas dirigidas à população em geral, com a finalidade de conscientizá-la e sensibilizá-la quanto à acessibilidade e à integração social da pessoa portadora de deficiência ou com mobilidade reduzida.

Veja-se que a partir do primeiro ano de vigência da norma, deveriam ter sido eliminadas as barreiras arquitetônicas de todas as construções da Administração Pública Federal, direta e indireta. É certo que algumas modificações já foram feitas, mas será que somente o que já foi feito basta? $\mathrm{O}$ que se percebe é que os estabelecimentos penais estão sendo esquecidos pelas autoridades.

Por sua vez, a Lei n. 10.048/00 veio para dar prioridade ao atendimento de pessoas portadoras de deficiência física, dentre outras classes de pessoas com limitação, mesmo que provisória.

Esta lei é muito aplicada em bancos, os quais dão atendimento preferencial a gestantes, lactantes, pessoas acompanhadas de crianças de colo e aos portadores de necessidades especiais. Mas não é nosso intuito tal utilização.

O que queremos destacar desta lei é o contido em seu artigo quarto:

Art. 4 Os logradouros e sanitários públicos, bem como os edifícios de uso público, terão normas de construção, para efeito de licenciamento da respectiva edificação, baixadas pela autoridade competente, destinadas a facilitar o acesso e uso desses locais pelas pessoas portadoras de deficiência.

Tratam-se de modificações a fim de facilitar o acesso e uso de locais como logradouros e sanitários públicos pelas pessoas portadoras de deficiências. Como já salientado, algumas reformas já foram feitas. Outras foram feitas sem foco. Exemplo disso e que muitos fóruns não tem adaptações, muito embora 
já estarmos no ano de 2010. O fórum de Xaxim, por exemplo, sofreu reforma em sua estrutura e após seu término, constatou-se a presença de um elevador (adaptado para deficientes físicos) para que o necessitado pudesse deslocar-se até o segundo piso do prédio. Muito boa intenção do arquiteto, porém há um problema: no acesso ao fórum há somente uma escada, sendo que, se um cadeirante tiver audiência no segundo piso, terá que entrar pelos fundos do prédio, dar uma volta interna até a frente e aí sim, utilizar-se do elevador.

São situações simples, mas que causam um grande obstáculo à pessoa sem acessibilidade.

Finalmente, a Lei n. 7.853/89, trata do apoio às pessoas portadoras de deficiência física, bem como de sua integração social. Possui ela vinte artigos, todos destinados ao cumprimento de sua proposta.

$\mathrm{O}$ artigo primeiro dita as regras gerais para o pleno exercício dos direitos individuais e sociais das pessoas portadoras de deficiências, e sua efetiva integração social. Em seu inciso cinco, há especificação para a área das edificações, conforme se observa:

V - na área das edificações:

a) a adoção e a efetiva execução de normas que garantam a funcionalidade das edificações e vias públicas, que evitem ou removam os óbices às pessoas portadoras de deficiência, permitam o acesso destas a edifícios, a logradouros e a meios de transporte.

Mais uma vez, a legislação quer que os obstáculos arquitetônicos sejam abolidos, pois é a primeira forma de trazer à sociedade o pleno convívio com aqueles que não saem de casa por falta de estrutura para sua recepção. Analogicamente se falando, nas três leis estudadas as previsões são claras, querendo a acessibilidade dos excluídos por calçadas sem rampas, escadas gigantes e portas minúsculas. O legislativo clama pela adequação 
dos logradouros públicos e privados, mas parece que a Administração não quer ver isso. $\mathrm{O}$ que se pode fazer então? Para onde devemos correr?

Existe também outro problema relacionado ao estabelecimento penal e à mantença de presos com deficiência física, agora de ordem médica. A impossibilidade de locomoção faz com que feridas apareçam nos membros inferiores dos recolhidos, causando maior sofrimento intra-cárcere, uma vez que tais ferimentos são de difícil cicatrização e em caso de não cuidado/tratamento, corre-se o risco de amputação e surgimento de câncer no local. Certa também é a afirmação de que as casas penitenciárias não têm assistência à saúde.

Como qualquer pessoa, o condenado é suscetível a contrair doenças, sejam elas provenientes do cárcere, ou não. O certo é que o estabelecimento penal deve estar provido de profissional habilitado para o atendimento de situações rotineiras e excepcionais. Ou seja, necessária se faz a presença de uma equipe multidisciplinar capacitada para atender às necessidades do preso portador de deficiência física.

Diante de todo o exposto, fica a pergunta: qual a implicação do Princípio da Dignidade da Pessoa Humana frente às necessidades especiais do preso.

Como já discutido tem-se por princípio da dignidade da pessoa humana um valor de extrema relevância que nasce com a pessoa e a acompanham por toda vida. Constitui este valor num mínimo não disponível que merece ter destaque em qualquer legislação que garanta direitos, como é o caso de nossa Magna Carta (MORAES, 2007, p. 80-81).

Todos os doutrinadores de Direito Constitucional são unânimes ao se referirem ao princípio da dignidade humana como sendo a essência do ser humano e que ele não é apenas mais um direito no meio dos demais: é o núcleo dos direitos, pois sem ele talvez os demais não tivessem como ser efetivados (SARLET, 2001, p. 54; KIRST, 2010). 
Por essa razão, tal princípio deve ser tratado como ouro em cofre, merecendo total segurança em sua preservação. Exemplo disso é o limite imposto ao Poder Público no sentido de não violar a dignidade da pessoa no exercício de sua cidadania. Por outro lado, há a determinação ao Estado de concretizar uma vida com dignidade para todos (SARLET, 2001, p. 108).

Da mesma forma, não restam dúvidas "de que a dignidade da pessoa humana engloba necessariamente respeito e proteção da integridade física e emocional em geral da pessoa" (SARLET, 2001, p. 89), tanto que "o respeito pela dignidade das pessoas começa em pequenas coisas, em atitudes simples, na constatação de que é no dia-a-dia que se constrói uma sociedade mais digna, justa e solidária" (NUNES, 2002, p. IX).

Neste sentir, a Constituição traz em seu texto diversas garantias e preceitos inerentes ao Direito Penal e à pessoa do preso. Dentre esses preceitos está a dignidade da pessoa humana, que apesar de não ser matéria específica é possível sua invocação, por identificar-se com a situação frágil em que ele se encontra (JESUS, 2010). Mas será que a dignidade humana está presente nos estabelecimentos penais?

Mesmo estando este princípio previsto no ordenamento jurídico brasileiro, verifica-se sua não consagração, uma vez que os estabelecimentos carcerários estão em situação assombrosa, totalmente desprovidos de atenção e consideração por parte do Estado e de seus agentes (KIRST, 2010), mesmo sendo notório que o princípio em questão é irrenunciável e que existe ainda que o Direito não a reconheça (SARLET, 2001, p. 80-81).

Assim, "bem se sabe que a realidade dos presídios e delegacias brasileiras está longe do aceitável, e mais longe ainda de alcançar a finalidade que lhes deveria ser atribuída" (JESUS, 2010). Todos os dias os meios de comunicação mostram "situações de miséria a que são expostos os internos” (JESUS, 2010). A pena deixa de apresentar seu caráter principal, qual seja, a de ressocialização, apresentando-se aos condenados como tripla punição como destacado: 
porque primeiramente são punidos pelo juiz; posteriormente, dentro do presídio, ao sofrerem agressões advindas dos próprios pares, ou então dos agentes carcerários; e finalmente, quando deixam a prisão, seja porque já pagaram sua divida, ou porque conseguiram regime diferenciado de cumprimento de pena, são punidos pela sociedade (JESUS, 2010).

Analisa-se de forma crítica a realidade dos estabelecimentos carcerários, demonstrando a total ausência de condições dignas nestes locais, constituindo tal fato grave afronta aos Direitos Humanos e à nossa Constituição Federal. Temos, na verdade, "uma sociedade e um Estado cujas posturas são carregadas de inaceitável desprezo e omissão em relação às pessoas encarceradas (KIRST, 2010).

Neste diapasão, "é evidente que os presos estão sendo condenados a passar fome, passar frio, a viver amontoados, virar pasto sexual e contrair AIDS e tuberculose nos estabelecimentos prisionais (KIRST, 2010). Tudo isso é grande afronta à nossa legislação constitucional, tanto que Kirst (2010) questiona-se: "há possibilidade de se afirmar que não existem penas cruéis?"

Nisso tudo "vê-se um quadro doloroso nos presídios, que retrata um dia a dia repleto de contrariedades em relação ao sistema" (KIRST, 2010) positivado em nosso país. Atrevo-me a dizer, inclusive, que "existe uma grande falta de vontade do Estado em investir no setor carcerário" (KIRST, 2010), pois "onde existe firme vontade, não há lugar para o fracasso" (KIRST, 2010).

De outro norte, temos o conceito de portador de deficiência física, sendo uma "restrição física, mental ou sensorial, de natureza permanente ou transitória, que limita a capacidade de exercer uma ou mais atividades essenciais à vida diária, causada ou agravada pelo ambiente econômico e social" (MAZZILI, 2003, p. 514). A defesa dos direitos das pessoas com restrições "dependem da luta ideológica no sentido de fazê-los prevalecer como conteúdos da vontade geral” (ASSIS, 2005, p. 54). 
Por mais simples que seja subir escadas, atravessar a rua e 'pegar' um ônibus, para o deficiente físico tudo isso é um grande desafio. Digo desafio não no sentido de que seja impossível para eles, ou que eles são inúteis para tanto, mas em razão da falta de consciência por parte do resto das pessoas que se dizem normais em ver a realidade. "Entretanto, todas essas condições em nada diminuem a dignidade do ser humano" (MAZZILI, 2003, p. 514), pois os portadores de necessidades especiais sempre superam seus problemas, ao contrário de muitos de nós, que reclamam da vida.

Passamos agora a discutir o processo de inclusão. Afinal, do que estamos falando quando falamos de inclusão? "A inclusão é um conceito amplo trabalhado em vários campos do conhecimento, cujo sentido vem se constituindo atendendo a diversos interesses" (ROBERT, 1999, p. 118). Do dicionário, incluir significa "inserir num ou fazer parte de um grupo" (PRIBERAM, 2010). Assim, devemos nos incluir no grupo das pessoas com necessidades especiais e entender seu desenvolver diário. Perceber que pequenas coisas fazem a diferença. "Seria chover no molhado a simples afirmativa de que o deficiente sofre limitações" (ROBERT, 1999, p. 11), pois se coisas consideradas simples são obstáculos que impedem a pessoa portadora de necessidades especiais de se integrar na sociedade, imagine como é ser um preso deficiente físico.

A administração dos centros penitenciários fica a cargo do Poder Executivo de cada Estado-membro por intermédio das Secretarias de Justiça ou de Segurança Pública que, observando as regras gerais nacionais sobre Direito Penitenciário, criam as normas suplementares, conforme artigo 24, parágrafo segundo, da Constituição Federal de 1988, que são necessárias à disciplina dos estabelecimentos. Mas o que foi feito até agora para assegurar a aplicação do princípio da dignidade da pessoa humana para os presos sem limitação motora? Nada. Imagine então quanto àqueles que têm limitação! 
O que se quer com este trabalho é buscar se providencie um mínimo de estrutura nos estabelecimentos penais para a recepção de qualquer modalidade de preso, seja ele considerado normal ou não. A dignidade dentro das casas de privação de liberdade deve ser o mínimo oferecido a eles. Sua condição de pessoas que agem fora dos ditames da lei não deve se estender ao cumprimento de pena, pois sua função básica é a ressocialização. Mas como falar nisso sem dignidade no cumprimento da pena.

Agora é possível que surja a seguinte indagação: sabe-se o índice de pessoas portadoras de deficiência que cometem delitos é baixíssimo e com este trabalho se pretende defender a melhoria de condições somente aos presos possuidores de deficiência? Como fica o resto da população carcerária? Entretanto, a questão requer uma reflexão.

Há quantos anos existe a prisão? Muitos. E desde sua 'instalação' até os dias de hoje, quais foram as melhoras, em termos de estrutura e condições, para presos "normais"? Nenhuma. Se até hoje nada foi feitos para eles, o que será feito para aqueles que precisam de mais atenção?

Veja-se que não se pretende neste trabalho dar ênfase de super stars (estrelas) para os presos que possuem alguma espécie de deficiência física, ou tratá-los melhor por sua condição. $\mathrm{O}$ que se pretende é demonstrar a realidade do atual sistema penitenciário, no que concerne à falta de estrutura física para a recepção de presos com limitação. Utilizou-se o paraplégico como ator principal, mas poderia ser um esquizofrênico ou uma pessoa com epilepsia. $\mathrm{O}$ que se pretende com todo o exposto, é demonstrar a falta de estrutura nas assistências física, material, médica, odontológica, psíquica e social, intra cárcere, pois a condição de sujeito privado de sua liberdade não tira seus direitos assegurados pelo Mandamus Constitucional.

Ademais, outros complexos prisionais já foram inaugurados com adaptações para deficientes físicos. Exemplo disso é o Centro de Detenção e Ressocialização de Foz do Iguaçu, 
inaugurado em 23 de outubro de 2008 (REQUIÃO, 2008), e a Penitenciária de Ribeirão Preto/MG, inaugurada em 15 de agosto de 2000.

Outra opção para adaptação, no que se refere aos sanitários, é a substituição dos "bois" por vasos sanitários acima do nível do chão e com barras laterais de apoio, como grande parte dos edifícios comerciais apresentam.

No que tange às celas, propõe-se o alargamento das portas e a utilização de rampas adequadas e bem feitas, pois somente assim será dada a devida aplicação do princípio da dignidade da pessoa humana poderá ser empregado, satisfazendo a todos os apenados, sejam ou não portadores de alguma deficiência física.

Inegável que não seria conveniente ou oportuno para a Administração demolir todos os estabelecimentos penais existentes e construir novos, com as adaptações devidas, pois seria economicamente inviável. Por isso mesmo, a proposta deste estudo é a adaptação daqueles que já estão construídos. Desta maneira, além de economizar recursos públicos, já tão escassos, o Estado atenderia aquilo que determina a Constituição Federal e as leis específicas.

Por fim, cabe ainda salientar que a adaptação de espaços nos presídios e penitenciárias é uma das medidas necessárias para trazer o respeito ao princípio da dignidade da pessoa humana aos encarcerados, obtendo-se com eficiência o fim da ressocialização.

\section{CONCLUSÃO}

Desde seu nascimento o cumprimento da pena passou por diversas mudanças: era ante sala do julgamento definitivo ou servia apenas para castigar religiosos pecadores. Durante séculos as mudanças propiciaram a readaptação da função das prisões, tanto que hoje possui o desafio de integrar o preso à sociedade.

Pela mesma experiência de aprimoramento passaram os princípios. Inicialmente, não tinham relevância, mas nos dias 
de hoje desfrutam de patamar inigualável no ordenamento jurídico, de tal forma a serem considerados alicerces do sistema, influenciando, inclusive, na tomada de decisões.

E é com base nos princípios que as leis infraconstitucionais são (ou devem ser) aplicadas. Contudo algumas considerações merecem destaque.

A Lei de Execução Penal, por exemplo, foi criada com o objetivo de efetivar as disposições da sentença ou da decisão criminal a fim de proporcionar condições para a harmônica integração social do condenado ou do internado e deixa bem claro que não haverá qualquer distinção de natureza racial, social, religiosa ou política.

Contudo, a mesma lei dispõe que os condenados serão classificados, segundo os seus antecedentes e personalidade, para orientar a individualização da execução penal.

Aí vem a pergunta: e se o preso for portador de alguma deficiência física? Qual vai ser a forma de individualizar sua pena? Desta forma buscou-se averiguar se o Princípio da Dignidade da Pessoa Humana está sendo observado na atualidade.

Baseado nisso, este trabalho visou demonstrar que as casas penitenciárias não estão prontas para a recepção de detentos com essas particularidades, e mais, visou inclusive encontrar formas de adequar os estabelecimentos visando, sempre, a reinserção do mesmo à sociedade, uma vez que, não há estudo neste sentido.

No atinente ao Princípio da Dignidade da Pessoa Humana constatou-se seu pleno entrosamento com o objeto da presente pesquisa, uma vez que não há como se falar em cumprimento de pena, sem o mínimo de dignidade. Por mais que alguém tenha cometido um delito, não significa mereça tratamento desumano.

Enfatiza-se novamente que este trabalho não buscou dar tratamento de estrela ao preso portador de deficiência física, nem defender a idéia de proteção pela sua condição. A sustentação desta pesquisa baseou-se na demonstração da falta de 
estrutura física nos estabelecimentos carcerários da região oeste de Santa Catarina, quanto a possibilidade de recepção de presos com limitações físicas, de modo a reforçar a ideia de que sua condição de debilitado não retira seu direito de cumprimento de pena com dignidade.

\begin{abstract}
This study addresses broadly the correlation between the Principle of Human Dignity and the inmate with special needs, their maintenance in terms intra-jail. It aims at mapping the physical conditions of prisons, to examine whether legislation establishes rules and guidelines regarding the adequacy of legal and physical prison, examining the existence of treatment and support to help care for people with special needs in prison houses, verify that the prisons are appropriate and/or are able to receive prisoners with disabilities and to investigate what are the rights that have special needs with the current society. At the end is expected to have contributed to society in order to inform people about the subject matter, namely, the fit of the prison system for the reception of prisoners with physical disabilities, a topic that requires the participation of the entire society and the Government for its solution, for these people also have in their favor the principle of human dignity with regard to compliance with the restriction of their freedom.
\end{abstract}

Keywords: Human dignity. Arrested. Special needs.

\title{
REFERÊNCIAS
}

ASSIS, Olney Queiroz. Pessoa portadora de deficiência: direitos e garantias. 2. Ed. São Paulo: Damásio de Jesus, 2005.

BALDI, César Augusto. Tratados internacionais podem ampliar direitos. Revista Consultor Jurídico, São Paulo, 13 set. 2009. Disponivel em: <http:// www.conjur.com.br/2009-nov-13/tratados-internacionais-ampliam-direitospessoas-deficiencia>. Acesso em: 04 mai. 2010. 
BRASIL. Constituição: República Federativa do Brasil de 1988. Brasília, DF: Senado Federal, 1988.

. Código de Processo Penal e Constituição Federal. 15. ed. São Paulo: Saraiva, 2009.

. Códigos Civil; Comercial; Processo Civil e Constituição Federal. 5. ed. São Paulo: Saraiva, 2009.

. Lei n. 7.210, de 11 de julho de 1984. Disponível em: <http:// www.planalto.gov.br/ccivil/leis/L7210.htm>.

. Lei n. 7.853, de 24 de outubro de 1989. Disponível em: <http:// www.planalto.gov.br/ccivil_03/Leis/L7853.htm>.

. Lei n. 10.098, de 19 de dezembro de 2000. Disponível em: <http://www.planalto.gov.br/ccivil_03/Leis/L10098.htm>.

. Lei n. 10.048, de 08 de novembro de 2000. Disponível em: <http://www.planalto.gov.br/ccivil_03/Leis/L10048.htm>.

CAMARGO, Virginia da Conceição. Realidade do sistema prisional. 25 out, 2006. Disponivel em: <http://www.direitonet.com.br/artigos/ exibir/2971/Realidade-do-sistema-prisional >. Acesso em 15 fev. 2010.

CANOTILHO, J. J. Gomes. Direito constitucional e teoria da constituição. 7. ed. Coimbra, Portugal: Almedina, [200-]. 1522 p.

FERREIRA, Aurélio Buarque de Holanda. Novo Dicionário Aurélio da língua portuguesa. 3. ed. Curitiba: Positivo, 2008.

JESUS, Joseane A. S. de. O princípio da dignidade da pessoa humana e a realidade do sistema prisional brasileiro. Disponível em: $<\mathrm{http}: / /$ jusvi. com/artigos/33136>. Acesso em 15 fev. 2010.

KIRST, Carolina Pereira. O princípio da dignidade humana frente ao sistema prisional: graves omissões e contradições em relação à legislação vigente. Jus Navigandi, Teresina, ano 13, n. 2082, 14 mar. 2009. Disponível em: <http://jus2.uol.com.br/doutrina/texto.asp?id=12461〉. Acesso em: 20 jan. 2010.

LIMA, Bartira Mousinho. A falência do sistema carcerário. Disponível em: < http://www.advogado.adv.br/estudantesdireito/uniceuma/ bartiramousinholima/falenciasistemacarcerario.htm>. Acesso em: 09 ago. 2010. 
MARTINS, Flademir Jerônimo Belinati. Dignidade da pessoa humana: princípio constitucional fundamental. 1. ed, (ano 2003), 2a tir. Curitiba: Juruá, 2004.

MAZZILLI, Hugo Nigro. A defesa dos interesses difusos em juízo: meio ambiente, consumidor, patrimônio cultural, patrimônio público e outros interesses. 16. ed. rev., ampl. e atual - São Paulo: Saraiva, 2003.

MIRABETE, Julio Fabbrini. Execução Penal: comentários à Lei n. 7.210, de 11-7-1984. São Paulo: Atlas, 2007.

, Julio Fabbrini. Fontes do direito processual penal. Disponível em: <http://www.leonildocorrea.adv.br/curso/mira4.htm>. Acesso em: 22 set. 2010.

MORAES, Alexandre de. Constituição do Brasil interpretada e legislação constitucional. 7. ed. atualizada até a EC no 55/07 - São Paulo: Atlas, 2007.

NUNES, Luiz Antônio Rizatto. O princípio constitucional da dignidade da pessoa humana: doutrina e jurisprudência. São Paulo: Saraiva, 2002.

OLIVEIRA, Adriana Leonidas de. et al. Mídia e representação social do sistema penitenciário brasileiro. 2007, Brasília. Disponível em: <http://www.vjirs.com.br/vjirs/anais-online-resumos-detalhe. asp?id=172\&idad=520>. Acesso em 30 ago. 2010.

OLIVEIRA, Moacyr de. Deficientes: sua tutela jurídica. Revista dos Tribunais. São Paulo/SP, v. 553, p. 11/17, nov. 1981.

PRIBERAM. Dicionário Priberam da Língua Portuguesa. Disponível em <http://www.priberam.pt/dlpo/>, acesso em: 19 jul 2010.

REQUIÃO INAUGURA a melhor penitenciária do PR. Umuarama Ilustrado. 24 out. 2008. Disponível em: <http://www.ilustrado.com.br/ arquivo/241008/pagina3.pdf $>$. Acesso em 27 mar. 2010.

ROBERT, Cinthia. O direito do deficiente. Rio de Janeiro: Lumen Juris, 1999.

SARLET, Ingo Wolfgang. Dignidade da pessoa humana e direitos fundamentais na Constituição Federal de 1988. Porto Alegre: Livraria do Advogado, 2001. 
SAVAZZONI, Simone de Alcântara. Os direitos das pessoas portadoras de deficiência em cumprimento de pena. Disponível em $<$ http://www.lfg. com.br/public html/article.php?story $=20090216150257672>$. Acesso em: 20 jan. 2010. 